\section{Microhardness characteristics values of root canal dentin after application with different types of EDTA}

\author{
Wahyuniwati, Juni J. Nugroho, Aries C. Trilaksana, Christine A. Rovani, \\ Nurhayaty Natsir, Indrya K. Mattulada
}

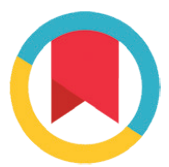

CrossMark

Abstract

Objective: The aim of the study was to determine the characteristics of the microhardness impairment root canal dentin after application with different types of EDTA.

Material and Methods: The teeth were decoronated at Cementoenamel junction (CEJ), prepared by the crown down pressureless technique, cut along the longitudinal direction and each sample was attached to self-cured acrylic and then soaked in distilled water. Samples were subjected to early microhardness measurement by means of digital vickers microhardness tester. The sample was then applied to the appropriate group of EDTA materials for 5 minutes, except for the negative control group, soaked in saline solution for
5 minutes and then the final measurement of microhardness of dentin was performed. Data were collected and analyzed using Anova and Tukey's post hoc test.

Results: The results showed that there were differences in dentin microhardness which decreased significantly in all treatment groups compared to the negative control group $(p<0.05)$, but with the largest drop in the EDTA solution group which amounted to $13667 \mathrm{~kg} / \mathrm{mm} 2$.

Conclusion: This present research it can be concluded that EDTA application may decrease root canal dentin microhardness value.
Department of Conservative Dentistry, Faculty of Dentistry, Hasanuddin University, Makassar, Indonesia
*Correspondence to: Wahyuniwati, Department of Conservative Dentistry, Faculty of Dentistry, Hasanuddin University, Makassar, Indonesia

indryamattulada@yahoo.com

Received: 18 February 2016

Revised: 25 April 2016

Accepted: 26 April 2016

Available Online: 30 April 2016

Keywords: Microhardness, EDTA, Surfactant, Root canal dentin

Cite This Article: Wahyuniwati, Nugroho JJ, Trilaksana AC, Rovani CA, Natsir N, Mattulada IK. 2016. Microhardness characteristics valuesof root canal dentin after application with different types of EDTA. Journal of Dentomaxillofacial Science 1(1): 49-52. D0I: 10.15562/jdmfs.v1i1.25

\section{Introduction}

One of the stages of root canal treatment is instrumentation that requires an irrigation solution to remove remaining organic and inorganic substances which are produced from treatment procedure. ${ }^{1,2}$ Irrigation solution throughout the instrumentation has several intentions such as antibacterial activity, dissolving system ability and chelating property. ${ }^{1,3}$ Previous research showed that the irrigation solution which significantly changed the mineral composition of root canal dentin. Particularly, the chelating ingredient that acted upon by affecting mineral component in dentin. ${ }^{3,4}$

Chelating substance that has commonly been used is EDTA (etylene diaminete traacetic acid)., Different types of EDTA have been widely used in root canals treatment, generally paste or cream, gel and solution form. ${ }^{6}$ EDTA is a chelating material that is attached to classified component (particularly calcium ion) and it is able to attract calcium ion from dentin which causes demineralization and soften the dentin. ${ }^{5-9}$ The action of EDTA can be effectively increased by reducing the surface tension. Surfactant is a material that can diminish surface tension. It is also added to EDTA to improve cleaning effect and penetration ability of dentin..$^{5-7}$

The reduction of dentin microhardness is useful to clinical condition when enable fast preparation and narrow root canal negotiation. Despite softening the dentin and demineralization it affects the physicochemical property of dentin structure. ${ }^{6,10,11}$

Dentin microhardness is sensitive towards the change of composition on the teeth surface. ${ }^{12,13}$ In spite of the reduction of microhardness of the dentin root canal, the instrumentation can make teeth structure get weaker and increase the incidence of fracture risk and/or crack. ${ }^{3,11}$ Determination of microhardness can provide indirect removal of mineral substance from dental hard tissue. It is important to know the effects of chemical substance (such as EDTA) which is used toward microhardness of root canal dentin. ${ }^{3,7,11,12}$

\section{Material and Methods}

Sample that required inclusion criteria was taken and decoronated to CEJ. Root canal preparation was done using hand instrument ProTaper (Dentsply, Switzerland) up to F5. Each of the file changing was copiously irrigated by $2.5 \% \mathrm{NaOCL}$. After preparation, sample was then immersed in aquades. It was split to longitudinal direction, and then it was embedded in self-curing acrylic resin and divided into 4 groups EDTA solution, 
EDTA gel, EDTA cream and negative control (6 each).

Early measurement of dentin microhardness of samples was done by using digital vickers microhardness tester. EDTA was applied to sample within 5 minutes, then it was rinsed with $2.5 \%$ $\mathrm{NaOCl}$ and dried using paper point and the dentin microhardness was measured to 3 points: coronal, middle and apical. The average value out of 3 was proved as the sample VHN value.

\section{Results}

Table 1 and figure 1 show before EDTA application, the average of dentin microhardness at EDTA solution, EDTA cream, EDTA gel, and negative control groups was presented in order: $63.727 \mathrm{~kg} / \mathrm{mm}^{2}$,

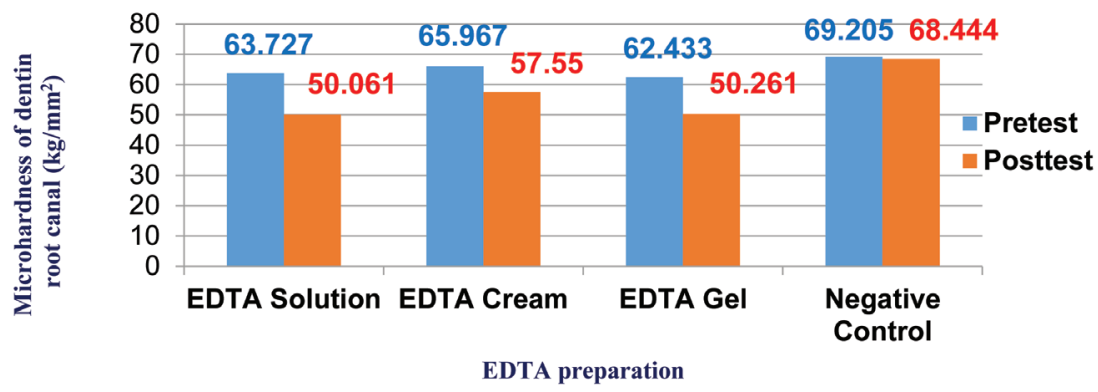

Figure 1 Dentin microhardness value distribution before and after application of each EDTA preparation
$65.967 \mathrm{~kg} / \mathrm{mm}^{2}, \quad 62.433 \mathrm{~kg} / \mathrm{mm}^{2}$ and 69.205 $\mathrm{kg} / \mathrm{mm}^{2}$ respectively. After the application to all groups, the dentin microhardness decreased to $50.061 \mathrm{~kg} / \mathrm{mm}^{2}, 7.550 \mathrm{~kg} / \mathrm{mm}^{2}, 50.261 \mathrm{~kg} / \mathrm{mm}^{2}$ and $68.444 \mathrm{~kg} / \mathrm{mm}^{2}$ respectively.

The result of statistical test of paired sample $\mathrm{t}$-test showed $\mathrm{p}<0.05$ to all groups. It reveals that there is a significant difference regarding the dentin microhardness value before and after application of EDTA solution (p:0.005: $\mathrm{p}<0.05)$, before and after application of EDTA cream (p:0.001: $\mathrm{p}<0.05)$, before and after application of EDTA gel (p:0.001: $\mathrm{p}<0.05)$ and also before and after application in negative control group ( $\mathrm{p}: 0.021: \mathrm{p}<0.05)$.

The decreased of dentin microhardness was mostly found in EDTA solution group, i.e., $13.667 \mathrm{~kg} / \mathrm{mm}^{2}$, whereas EDTA gel group took the second place $12.172 \mathrm{~kg} / \mathrm{mm}^{2}$. The least decreased of microhardness was at the negative control group $0.761 \mathrm{~kg} / \mathrm{mm}^{2}$ and the EDTA cream application reached $8.416 \mathrm{~kg} / \mathrm{mm}^{2}$. Through statistical test result, one-way Anova, it was found that p:0.000 $(p<0.05)$, this value showed the significant difference in dentin microhardness decreased among EDTA solution, cream and gel as well as negative control groups. To know the differences in microhardness among each group, it required post-testanalysis.

Table 2 shows the result of statistical difference, there is $p>0.05$ mark at the comparison between EDTA solution and cream, EDTA

Table 1 Dentin microhardness difference before and after application based on each EDTA preparations

\begin{tabular}{|c|c|c|c|c|}
\hline \multirow{3}{*}{$\begin{array}{c}\text { Preparation of } \\
\text { EDTA }\end{array}$} & \multirow[b]{3}{*}{ n (\%) } & \multicolumn{2}{|c|}{ Dentin Microhardness $\left(\mathrm{kg} / \mathrm{mm}^{2}\right)$} & \multirow[b]{3}{*}{$p$-value } \\
\hline & & Pretest & Posttest & \\
\hline & & Mean \pm SD & Mean \pm SD & \\
\hline Group 1: EDTA Sol. & $6(25 \%)$ & $63.727 \pm 1.371^{\mathrm{a}}$ & $50.061 \pm 7.195^{\mathrm{a}}$ & $0.005^{\star}$ \\
\hline Group 2. EDTA Cream & $6(25 \%)$ & $65.967 \pm 3.161^{\mathrm{a}}$ & $57.550 \pm 4.197^{\mathrm{a}}$ & $0.001^{*}$ \\
\hline Group 3. EDTA Gel & $6(25 \%)$ & $62.433 \pm 1.474^{\mathrm{a}}$ & $50.261 \pm 2.207^{\mathrm{a}}$ & $0.000^{\star}$ \\
\hline Negative Control & $6(25 \%)$ & $69.205 \pm 12.032^{\mathrm{a}}$ & $68.444 \pm 11.988^{\mathrm{a}}$ & $0.021^{*}$ \\
\hline
\end{tabular}

"Normality test: Shapiro-Wilk test: $p>0.05$ data distribution normal

** Paired sample t-test: $p<0.05$ significant

Table 2 The result of advance test difference of dentin microhardness reduction among EDTA solution, cream and gel as well as control negative

\begin{tabular}{|c|c|c|c|c|}
\hline EDTA Preparation & Comparative & Mean Difference & $\begin{array}{c}95 \% \mathrm{Cl} \\
(\min -\max )\end{array}$ & $p$-value \\
\hline \multirow[t]{3}{*}{ Group 1 EDTA Sol. } & EDTA Cream & 5.2500 & $-1.217-11.717$ & 0.138 \\
\hline & EDTA Gel & 1.4944 & $-4.973-7.962$ & 0.915 \\
\hline & Neg. Control & 12.9056 & $6.438-19.373$ & $0.000^{\star}$ \\
\hline \multirow[t]{2}{*}{ Group 2. EDTA Cream } & EDTA Gel & -3.7556 & $-10.223-2.712$ & 0.388 \\
\hline & Neg. Control & 7.6556 & $1.188-14.123$ & $0.017^{\star}$ \\
\hline Group 3.EDTA Gel & Neg. Control & 11.4111 & $4.943-17.878$ & $0.000^{*}$ \\
\hline
\end{tabular}

${ }^{\star}$ Post Hoc Test: Tukey's HSD (Highly Significant Difference) test: $p<0.05$ significant 
solution and gel shows $\mathrm{p}>0.05$. The result indicates that there is no significant difference in the decreased of microhardness among EDTA solution, cream and gel.

\section{Discussion}

Ethylene diamine tetraacetic acid is useful to remove smear layer and lubricated root canal wall, but it has a weakness in changing the dentin physical property such as microhardness. Microhardness changes can make root canal instrumentation easier, but may cause weak dental structure. Microhardness specification provides indirect evidence toward the mineral loss of dental hard tissue. ${ }^{3,11,14}$

Table 1 and figure 1 shows the decrease of dentin microhardness value after EDTA application. The decrease of dentin microhardness is the sign of the changing inorganic component at root canal dentin due to chelation action from EDTA. This is closely related to the research of Sayin et al. ${ }^{7}$ concerning the effect EDTA application on dentin microhardness. They stated that a single EDTA is able to reduce dentin microhardness significantly. ${ }^{5}$

The same result was reported by Pimenta et al. ${ }^{15}$ who used different tool such as Knoop Hardness Tester, and concluded that there was a reduction in the value of dentin microhardness after the application of $15 \%$ EDTA. ${ }^{15}$ The root canal dentin microhardness depends on various tubular density of each root canal dentin surface area ${ }^{7}$ The dentin collagen degradation stated that tubular density influence the microhardness, if the density increase then the dentin microhardness will diminished. ${ }^{3,16}$

The dentin microhardness will be decreasing if it is tested from the surface to the deeper area. The increase in the number of opened dentinal tubules and peritubular dentin that are free near pulp has small resistance toward microhardness according to the intended test. ${ }^{16}$ There is aninverted correlation between dentin microhardness and dentin tubular density. ${ }^{12,16}$

The dentin tubules density near lumen is higher than periferry. This is caused by the reduction of intertubular dentin number and the addition of individual dentin tubules towards the pulp so that the increase of the number of dentin tubules from dentin peritubular near pulp has little resistance toward indentation test. ${ }^{7,17}$

In this research, it took 5 minutes for EDTA to contact with the root canal dentin since 5 minute duration is claimed as a realistic timing regarding to clinical application. ${ }^{5}$ The number of calcium ion missing with $17 \%$ EDTA increased along with the application duration.
Seventeen percent EDTA solution produced maximum value of the missing calcium along with the increase of application time. ${ }^{12}$

The result of this research showed that there was a significant difference of dentin microhardness decrease $(p<0.05)$ among EDTA solution, EDTA cream, EDTA gel and negative control groups, where a maximum decrease of dentin microhardness was found in EDTA solution group which was $13.667 \mathrm{~kg} / \mathrm{mm}^{2}$, EDTA gel took the second place as $12.172 \mathrm{~kg} / \mathrm{mm}^{2}$ and EDTA cream as 8.416 $\mathrm{kg} / \mathrm{mm}^{2}$

That 3 minutes after the application of EDTA it caused the decrease of dentin microhardness, the reduction value was more than other chelating material such as citric acid. ${ }^{18}$ Several studies recently, stated that $17 \%$ EDTA reduced microhardness in the first minute after material application and microhardness further reduces along with the growing of contact time. ${ }^{3,9,11,19}$ That $17 \%$ EDTA has potential to cause excessive dentin erosion if applied for more than 1 minute. ${ }^{7,8}$

Today, the function of EDTA as lubricant at instrumentation process is widely recommended using various concentration and addition of many surfactant. ${ }^{6,20}$ That EDTA requires addition of surfactant due to increase EDTA effectiveness toward its ability to decalcify inorganic component of dentin.?

Various EDTA preparations have been used in root canal treatment, but at this study as the table 2 has shown that the advance differential test of decreasing dentin microhardness among EDTA solution, cream and gel as well as negative control reveal $p>0.05$ mark at the comparison which means that there is no significant difference in decrease of dentin microhardness between EDTA solution and cream or EDTA solution and gel.

There is no significant difference in EDTA cream/gel usage compared to EDTA solution, even with the surfactant addition. ${ }^{21}$

The different study result is explained by Lee and Chen as well as Hulsmann et $a .^{6}{ }^{6}$ that claim that EDTA with paste and cream form are difficult to flow into the narrow apical area or contact the root canal because of its thickness and consistency, so caused its reaction and chemomechanical effect to be limited because only a few of the material reached the narrow root canal wall, so chelation action of EDTA in paste and cream form turned out to be limited compared to EDTA solution which has better flowing source that was able to flow to apical and penetrate deeper into dentin. ${ }^{6}$

The probability of different study result in which the gel preparation without surfactant is better than cream with surfactant that is caused by 
thicker cream consistency so that the flowing source is more limited than the gel. The weakness of this study is the lack of EDTA substance $\mathrm{pH}$ measurement, the inappropriate temperature application, less number of samples and various mineral contents in sample.

The usage of EDTA as lubricant in instrumentation process nowadays is highly recommended with various preparation and surfactant addition. ${ }^{6,20}$ That EDTA needed to be added with surfactant to increase EDTA affectivity regarding its ability to decalcify dentin inorganic component. ${ }^{7}$

The research of Akcay et al. ${ }^{7}$ reported that addition of surfactant to EDTA causes change in dentin structure that leads to the decrease of root canal dentin microhardness. Calcium and magnesium is common chemical that bonds to surfactant, but the effect of surfactant to dentin physically is not explained in endodontic literatures. ${ }^{7,13}$

\section{Conclusion}

According to the results of this present research, it can be concluded that EDTA application may decrease root canal dentin microhardness value. The EDTA solution, cream and gel application is statistically shown with a significant outcome compared to control group but not significant among three group tests due to decreased of value of root canal dentin microhardness.

\section{Conflict of Interest}

The authors report no conflict of interest.

\section{Reference}

1. Kandaswamy D, Venkatesh babu N. Root canal irrigants. J of Conserv Dent 2010;13: 256-260.

2. Cobankara FK, Erdogan H, Hamurcu M. Effect of chelating agents on the mineral content of root canal dentin. Oral Surg Oral Med Oral Pathol Oral Radio Endo 2011: 149-152.

3. Kandil HE, Labib AH, Alhadainy HA. Effect of different irrigant solutions on microhardness and smear layer removal of root canal dentin. Tanta Dent J 2014; 11: 1-11.
4. Goldberg IS. Effect of sodium hypochlorite on dentin microhardness. JOE 2004;30: 880-882.

5. Napte BD, Srinidhi SR. Evaluation of the action of chelating agents on the microhardness of superficial layer of root canal lumen dentin. World J of Dent 2014;5: 124-128.

6. Chen G, Chang YC. Effects of liquid-and paste-type of EDTA on smear layer removal during rotary root canal instrumentation. J Dent Science 2011;6: 41-47.

7. Akcay I, Sen BH. The Effect of surfactant addition to EDTA on microhardness of root dentin. JOE 2012;38: 704-706.

8. Akcay I. The efficacy of an experimental single solution vs alternate use of multiple irrigants on root canal dentin microhardness. J Clin Exp Dent 2013;5: 83-88.

9. Fernandez ML. In vitro study of erosion caused by EDTA on root canal dentin. Revista Odont. Mexicana 2012;16: 8-13.

10. Sayin TC. The Effect of EDTA, EGTA, EDTAC and tetracycline- $\mathrm{HCl}$ with and without subsequent $\mathrm{NaOCl}$ treatment on the microhardness of root canal dentin. Oral Surg Oral Med Oral Pathol Oral Radio Endo 2007;104: 418-424.

11. Zaparolli D, Saquy PC, Cruz-Filho AM. Effect of sodium hypochlorite and EDTA irrigation, individually and in alternation, on dentin microhardness at the furcation area of mandibular molars. Braz Den and J 2012;23: 654-658.

12. Thangaraj DN, Ballal V, Acharya SR. Determination of calcium loss and its effect on microhardness of root canal dentin following treatment with $17 \%$ EDTA solution at different time intervals-an in vitro study. Endodontology 2008: 9-14.

13. Pacios MG. Effect of calcium hydroxide pastes and vehicles on root canal dentin microhardness. Original Article 2014;4: 53-57.

14. Fedele GR. Antagonistic interaction between sodium hypochlorite, chlorhexidine, EDTA and citric acid. JOE 2012;38: 426-428.

15. Pimenta JA. Chitosan: Effect of a new chelating agent on the microhardness of root dentin. Braz Dent J 2012;23: 212-217.

16. Al-Ashou WM. The effect of two root canal irrigants and different instruments on dentin microhardness (In vitro sudy). Al-Rafidain Dent J 2011;11: 63-70.

17. Filho CAM. Effect of chelating solutions on microhardness of root canal lumen dentin. JOE 2011;37: 358-361.

18. ZahedM,ShalafiS,JafarsadehH.Ethylenediaminetetraacetic acid in endodontics. Europ J of Dent 2013;7: 135-137.

19. Al-Azzawi AK, Hussein IN. An in vitro evaluation the effect of endodontic irrigation solution on the microhardness of root canal dentin. MDJ 2011;8: 19-25.

20. Kinney JH, Marshall SJ, Marshall GW. The mechanical properties of human dentin: A critical review and re-evaluation of the dental literature. Crit Rev Oral Bio Med 2003;14: 13-4, 23-4.

21. Violich, Chandler. Smear layer in endodontics. Int Endo J 2010;43: 6-10.

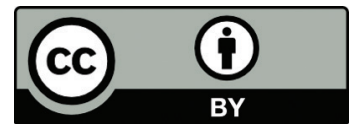

This work is licensed under a Creative Commons Attribution 